\title{
Diversity and distribution patterns of antennal sensilla in Hydropsychidae (Insecta, Trichoptera)
}

\author{
Kseniia Abu Diiak, Mikhail Valuyskiy, Stanislav Melnitsky, and \\ Vladimir Ivanov
}

Department of Entomology, Faculty of Biology, Saint Petersburg State University, Universitetskaya nab., 7-9, Saint Petersburg, 199034, Russian Federation

Address correspondence and requests for materials to Kseniia Abu Diiak, kdiyak@gmail.com

Citation: Abu Diiak, K., Valuyskiy, M., Melnitsky, S., and Ivanov, V. 2021. Diversity and distribution patterns of antennal sensilla in Hydropsychidae (Insecta, Trichoptera). Bio. Comm. 66(4): 302-315. https://doi.org/10.21638/spbu03.2021.403

Authors' information: Kseniia Abu Diiak, Student, orcid.org/0000-0003-2642-2247; Mikhail Valuyskiy, Master of Sci. in Biology, Assistant, orcid.org/0000-0001-9493-3626; Stanislav Melnitsky, PhD, orcid.org/00000003-4535-1886; Vladimir Ivanov, PhD, Associate Professor, Head of Department, orcid.org/0000-0003-3294-4965

Manuscript Editor: Maxim Vinarski, Laboratory of Macroecology and Biogeography of Invertebrates, Saint Petersburg State University, Saint Petersburg, Russia

Received: February 1, 2021;

Revised: April 14, 2021;

Accepted: June 3, 2021.

Copyright: (c) 2021 Abu Diiak et al. This is an open-access article distributed under the terms of the License Agreement with Saint Petersburg State University, which permits to the authors unrestricted distribution, and self-archiving free of charge.

Funding: The reported study was funded by RFBR, project number 18-04-00312, Saint Petersburg State University grants: Id: 28887890, Id: 30530084, Id: 32665611, Id: 33161520, Id: 33161571, Id: 37746533 and projects No. 109-16530 and 109-13295 of the Research Park of St. Petersburg State University, Center for Molecular and Cell Technologies.

Ethics statement: This paper does not contain any studies involving human participants or animals performed by any of the authors.

Competing interests: The authors have declared that no competing interests exist.

\begin{abstract}
Structure and distribution of antennal sensilla were studied in males of 19 species of the caddisfly family Hydropsychidae by using scanning electron microscopy (SEM). Eleven types of sensilla were found: Iong trichoid, chaetoid, thick chaetoid, curved trichoid, coronary, basiconic, styloconic and four types of pseudoplacoid sensilla (mushroom-like, auricillic, ribbed, and T-shaped). Thick chaetoid, ribbed pseudoplacoid, and T-shaped pseudoplacoid sensilla were found only in Macronematinae. The great diversity of pseudoplacoid sensilla originated from a mushroom-like type, which also has a variable structure. Basal flagellomeres in the majority of studied species are equipped with ventrally positioned sensory fields of curved trichoid sensilla. In contrast to Arctopsychinae and Hydropsychinae, the increased number of these sensilla in the fields was noted for Diplectroninae and Smicrideinae. Most Macronematinae show a reduction of sensory fields and a strongly decreased average number of curved trichoid sensilla on distal segments. The great differences found in the studied family probably indicate a rapid function-related evolution of the antennal sensory surface structures in the caddisfly family Hydropsychidae.
\end{abstract}

Keywords: sensilla, antenna, Hydropsychidae, Trichoptera

\section{Introduction}

Hydropsychidae (Annulipalpia) is a large and widespread family of net-spinning caddisflies which comprises about 2000 described species (Morse, 2020) and plays a significant role in freshwater ecosystems. Historically, this family comprised several annulipalpian families with presumably derived character conditions and was a source for erection of several related families; the last one was family Arctopsychidae (Martynov, 1924). The position of this group is still disputable as a primitive member of the phylum with few if any apomorphic characters: for example, a single ventral apotome with two subparallel ecdysial lines, mesoand metanotum sclerotized plates with transverse ecdysial line (Schefter, 1996). We consider here the family Hydropsychidae comprising five subfamilies with the most basal Arctopsychinae Martynov, 1924 and more advanced taxa Diplectroninae Ulmer, 1951; Smicrideinae Flint, 1974; Hydropsychinae Curtis, 1835; and Macronematinae Ulmer, 1905 (Morse, 2020). The phylogenetic relationships between subfamilies and within them were discussed in earlier studies based on molecular and morphological data (Kjer et al., 2016; Uy et al., 2019; Thomas et al., 2020).

The placement of Arctopsychinae together with the rest of hydropsychid taxa in the same phylogenetic clade is supported by a large amount of independently obtained morphological and molecular data (Schefter, 1996; Frania and Wiggins, 1997; Geraci et al., 2005). The family status of the Arctopsychidae has been confirmed several times since Martynov's study (Fischer, 1963; Schmid, 1968; Levanidova, 1982) with some arguments based on larval head, wing, and genital charac- 
ters (morphological data). Although the monophyly of all specified subfamilies except Diplectroninae is highly supported by morphological and molecular data, their taxonomic relationships and ranks are unclear in some cases (Schefter, 1996; Geraci et al., 2005; Geraci, 2007). We expect the implementation of a new character set, the antennal sensilla, to improve our knowledge on the taxonomy of this and related families and provisionally consider Arctopsychinae within Hydropsychidae to facilitate the comparison and discussion. Since family Hydropsychidae has significant structural diversity, studies of its sensory structures might contribute to the progress in our knowledge of the evolution of insect communication systems.

In comparison with other insects, caddisflies have an unexpectedly wide variety of antennal sensilla: More than 20 different types and subtypes of cuticular structures were found within the order Trichoptera (Melnitsky and Ivanov, 2011; Ivanov and Melnitsky, 2016). The antennal surface in Amphiesmenoptera initially includes six types of sensilla found in both Trichoptera and Lepidoptera: long trichoid, curved trichoid, pseudoplacoid, chaetoid, coronary and styloconic sensilla (Valuyskiy et al., 2020a). Antennal sensilla of caddisflies play a crucial role in olfactory reception and therefore in behavior and pheromone communication (Chapman, 1998; Sinitsina and Chaika, 2006; Melnitsky and Ivanov, 2011). Some cuticular structures (long trichoids, scales, and microtrichia) are not innervated and do not perform sensory functions (Snodgrass, 1935). Four types of sensilla distribution can be found on caddisfly antennae: Non-specific, when sensilla cover the whole surface of the segment and are distributed more or less uniformly; specific, when sensilla occur singly or in small groups only on certain parts of each segment; fixed, the sensilla have the same position on flagellomeres; and sensory fields, in which the sensilla occur in groups in certain places of each flagellomere - these groups comprise only one type of sensilla (Valuyskiy et al., 2017). The cuticular parts of sensilla in Trichoptera and Lepidoptera display considerable similarity (Faucheux, 2004).

Structure and distribution of antennal sensilla has been studied in several annulipalpian families: Philopotamidae (Melnitsky and Ivanov, 2011; Kubiak et al., 2015; Ivanov and Melnitsky, 2016; Melnitsky et al., 2018), Stenopsychidae (Melnitsky and Ivanov, 2011; Ivanov and Melnitsky, 2016), and the more advanced family Ecnomidae (Valuyskiy et al., 2019). These studies revealed the smaller diversity of sensilla in Annulipalpia, with 7 or fewer types of antennal sensory structures compared to over 15 types found in Integripalpia (Melnitsky and Ivanov, 2011; Ivanov and Melnitsky, 2016).

The distribution patterns of sensilla in these taxa have many similarities (Melnitsky et al., 2018; Valuyskiy et al., 2019). At the same time, the diversity of sen- silla is much higher in basal Integripalpia: 13 types of sensilla were found in Rhyacophilidae, mostly based on mushroom-like pseudoplacoid sensilla modifications (Valuyskiy et al., 2017). The distribution and number of sensilla show a significant variety in more advanced families of Plenitentoria, as found in the family Apataniidae (Valuyskiy et al., 2020b). The data available for two previously studied species of Hydropsychidae, Hydropsyche newae and H. contubernalis, are quite scarce (Melnitsky and Ivanov, 2011; Ivanov and Melnitsky, 2016). Therefore, additional data can help to estimate the diversity of cuticular structures and their distribution on the antennal surface for selection of all Hydropsychidae subfamilies. We believe that comparative studies of antennal sensilla in Hydropsychidae and related taxa are important for understanding the sensory physiology and communication behavior of these insects and would be beneficial for the taxonomic studies of Hydropsychidae.

\section{Material and methods}

We targeted this study to the male antennae because males are considered to play the active role in olfactory communication with the most developed sensory structures. The ultrastructure of antennal sensory surface in males of 19 species of the family Hydropsychidae was studied.

Studied species: Arctopsyche palpata Martynov, 1934 (Russia, Far East); Parapsyche apicalis (Banks, 1908) (Canada) (Arctopsychinae); Hydropsyche newae Kolenati, 1858 (Russia, Leningrad Region); H. orientalis Martynov, 1934 (Russia, Far East); H. pellucidula (Curtis, 1834) (Russia, Leningrad Region); Cheumatopsyche comorina (Navas, 1931) (Madagascar); Hydronema persica Martynov, 1914 (Kazakhstan, Turkistan Region) (Hydropsychinae); Diplectrona robusta Martynov, 1934 (Russia, North Caucasus); D.gombak Olah, 1993 (Malaysia); D.dulitensis Kimmins, 1955 (Malaysia); D. hermione Malicky, Chantaramongkol, 2002 (Malaysia) (Diplectroninae); Smicridea murina McLachlan, 1871 (Panama) (Smicrideinae); Centromacronema sp. (Peru); Leptonema viridianum $\mathrm{Na}$ vas, 1916 (Peru); Aethaloptera evanescens (McLachlan, 1880) (Russia, Buryatia); Amphipsyche gratiosa Navas, 1922 (Thailand); Macrostemum fenestratum (Albarda, 1881) (Malaysia); M. radiatum (McLachlan, 1872) (Russia, Buryatia); M.midas Malicky, Chantaramongkol, 1998 (Malaysia) (Macronematinae). Additional data on females of three species from the same family were obtained: L. viridianum Navas, 1916 (Peru); M.fenestratum (Albarda, 1881) (Malaysia); M. midas Malicky, Chantaramongkol, 1998 (Thailand, Samui) (Macronematinae). All the material was obtained from the collection of the Department of Entomology (St. Petersburg State University).

The study was carried out with scanning electron microscopy (SEM). All caddisflies used in this study 
were stored in ethanol. Antennae were removed, dried, mounted on specimen holders and covered with $20 \mathrm{~nm}$ gold coating in a Leica EM SCD500. Specimens were examined with the JEOL NeoScope JCM-5000 and Tescan MIRA 3 scanning electron microscopes which were provided by the Research Park of St. Petersburg State University.

Counting and measurements of sensilla through a series of microphotographs were made using ImageJ $1.52 \mathrm{a}$ software. Sensilla were manually counted on the visible surface of the segment, and the average numbers were recalculated for the whole surface according to the distribution pattern of the sensilla. In case of non-specific distribution, the number of sensilla was multiplied by 1.75 , because the dorsal surface of the segment bears less sensilla than the ventral (Valuyskiy et al., 2019). In a different case, when a segment bore two symmetrical sensory fields or clusters, but only one of them was visible, the number of sensilla was multiplied by 2 . The number of sensilla located singly or in small groups only on the certain area of each segment (specific distribution) was not recalculated. The mean values of the number of sensilla were calculated for groups of five segments $\left(1^{\text {st }}-5^{\text {th }}\right.$, $6^{\text {th }}-10^{\text {th }}$, etc.). Average size of every type of sensilla and standard errors were calculated based on 10 samples from different segments or from the same segment. All calculations were performed using MS Excel 2007.

\section{Results}

\section{Structure and diversity of sensilla on the flagellum in Hydropsychidae}

Eleven types of sensilla were identified on flagella of the studied hydropsychid species (Fig. 1). These structures are arranged in two layers due to different length. The upper layer contains long trichoid sensilla, curved trichoid sensilla, chaetoid sensilla and thick chaetoid sensilla. The lower layer comprises more types of sensilla of a smaller size: mushroom-like pseudoplacoid sensilla, auricillic pseudoplacoid sensilla, ribbed pseudoplacoid sensilla, T-shaped pseudoplacoid sensilla, coronary sensilla, basiconic sensilla and styloconic sensilla.

Long trichoid sensilla (Fig. 1A, B; 2A; 3A-B, D-F: lts) in all studied species are elongated structures with slightly asymmetrical sockets, narrowed bases and ribbed process, inclined towards the tip of antenna. They cover the whole surface of each segment except several places occupied by groups of other sensilla. The size of long trichoid sensilla varies from $21.7 \pm 0.8 \mu \mathrm{m}$ in M. fenestratum to $58.8 \pm 6.3 \mu \mathrm{m}$ in P.apicalis (Fig. 4A).

Sensilla of this type have longitudinal grooves and serration in Arctopsychinae, Hydropsychinae (except Hydronema persica), Diplectroninae and Smicrideinae. Significant reduction of long trichoid sensilla is observed in H.persica: These structures occur solitarily; they are shorter and smoother than in other species of the same subfamily. Antennae in all studied Macronematinae bear wide and flattened long trichoid sensilla which have oblique striation on both sides of the longitudinal axis (Fig. 1A). Some long trichoid sensilla on antennae of A. gratiosa, M. radiatum, M. fenestratum and M. midas are not flattened and have less pronounced striation.

Curved trichoid sensilla (Fig. 1E; 2B, F; 3A-F: cts) occur in all studied species. This type is shorter than other types of trichoid sensilla (from $10.3 \pm 0.4 \mu \mathrm{m}$ in Hydronema persica to $35.0 \pm 0.6 \mu \mathrm{m}$ in Centromacronema sp.) (Fig. 4C) and form more or less compact sensory fields on ventrolateral sides of flagellomeres. These sensilla have curved tips and annulate striation without visible pores.

Chaetoid sensilla (Fig. 1C; 2C; 3A-B, D-E: chs) are hair-shaped serrated structures disposed almost at a right angle to the cuticular surface, with large hemispherical sockets; they are found across the whole family. These sensilla significantly vary in size from $13.9 \pm 0.9 \mu \mathrm{m}$ in A. evanescens to $51.2 \pm 1.4 \mu \mathrm{m}$ in L.viridianum (Fig. 4B), but show no structural interspecific differences.

Thick chaetoid sensilla (Fig. 1D, 3E: tchs) is a distinctive derivative of chaetoid sensilla found only in Centromacronema sp. and A. evanescens. These are longitudinally striated hairs gradually narrowing towards the tip. These structures have rounded and widened sockets, which are slightly raised above the surface of the segment. The average length of these sensilla is $61.0 \pm$ $2.3 \mu \mathrm{m}$ in Centromacronema sp. and $32.8 \pm 1.5 \mu \mathrm{m}$ in A. evanescens.

Mushroom-like pseudoplacoid sensilla (Fig. $1 \mathrm{~K}-\mathrm{N}$, $2 \mathrm{H}, \mathrm{L} ; 3 \mathrm{~A}, \mathrm{C}-\mathrm{D}: \mathrm{mps}$ ) are generally present in studied species except D. robusta (Diplectroninae), Centromacronema sp., A.evanescens, A.gratiosa and M. radiatum (Macronematinae). Each sensillum has a widened apical part (a cap) attached to a thick and short stem. The apical surface is covered with grooves diverging from its center; these grooves contain numerous pores. The size of mushroom-like pseudoplacoid sensilla varies from $3.6 \pm$ $0.2 \mu \mathrm{m}$ in D. dulitensis and D. hermione to $9.9 \pm 0.3 \mu \mathrm{m}$ in L. viridianum. The lowest diameter of mushroom-like pseudoplacoid sensilla is observed in Diplectroninae (no more than $4 \mu \mathrm{m}$ ) (Fig. 4E).

In Arctopsychinae, Diplectroninae and Hydropsychinae mushroom-like pseudoplacoid sensilla are concave, with well-developed grooves and pores (Fig. 1M). In Ch. comorina the distal margin of the sensillar cap is elongated and has serration (Fig. 1N). Caps of mushroom-like pseudoplacoid sensilla have an oval shape in L. viridianum and M. midas (Fig. 1K). Antennae of S. murina bear elongated and slightly pointed mushroom-like pseudoplacoid sensilla, with proximal margin fused with the surface of the segment (Fig. 1L). In this 

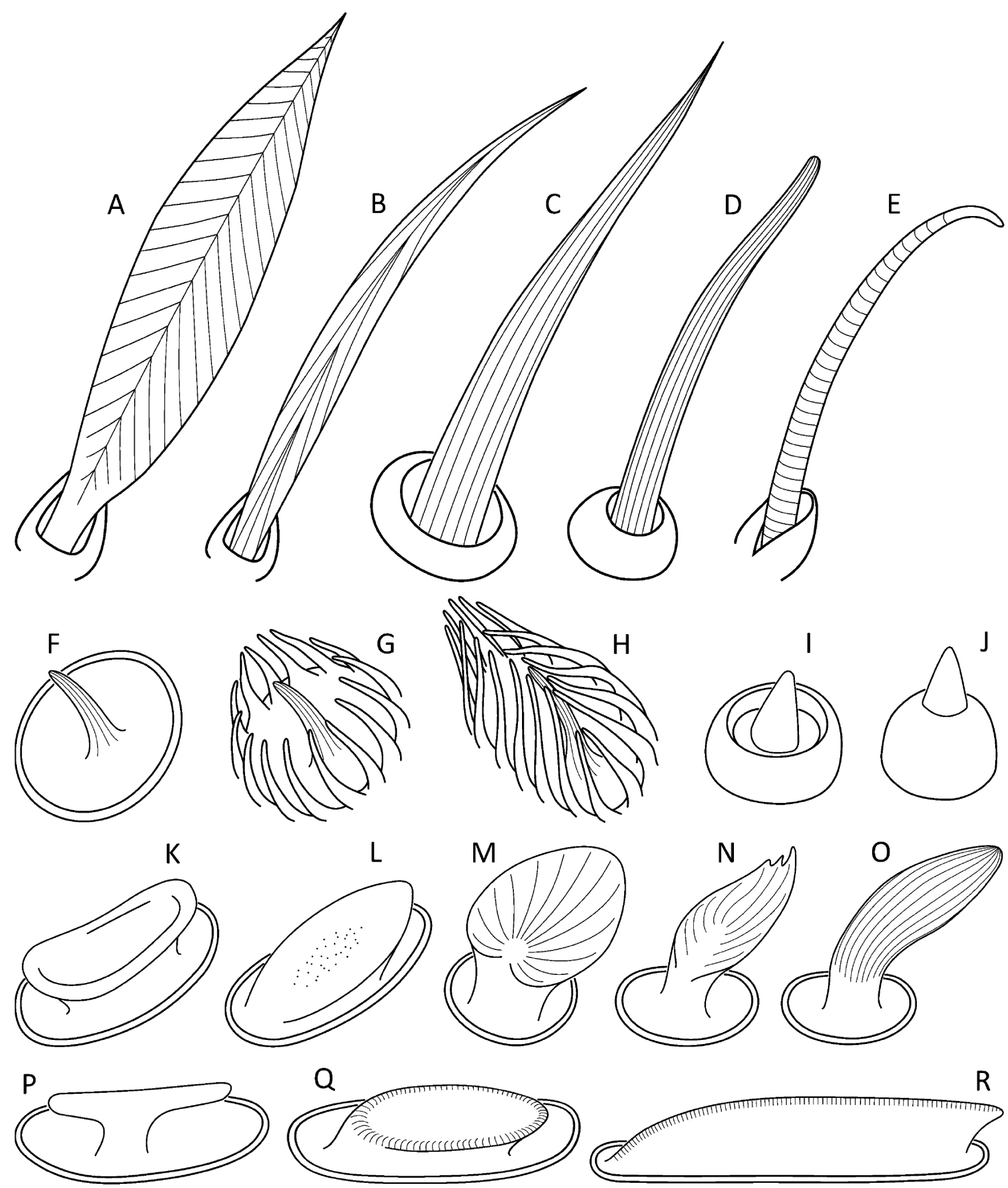

Fig. 1. Types of sensilla in Hydropsychidae

A-B - Iong trichoid; C - thick chaetoid; D - chaetoid; E - curved trichoid; F - basiconic; G-H - coronary; I-J - styloconic; K-N mushroom-like pseudoplacoid; O — auricillic pseudoplacoid; P — T-shaped pseudoplacoid; Q-R — ribbed pseudoplacoid.

case their apical parts have relatively small number of pores.

Auricillic pseudoplacoid sensilla (Fig. 1O; 2A, I, $\mathrm{L} ; 3 \mathrm{~F}$ : aus) is a modified mushroom-like sensilla subtype found in D. robusta, A.evanescens, A.gratiosa, M.fenestratum and M. radiatum. Their length varies from $4.6 \pm$ $0.2 \mu \mathrm{m}$ in A.gratiosa to $7.5 \pm 0.3 \mu \mathrm{m}$ in D. robusta. In contrast to the wide and flat auricillic sensilla in Lepi- 

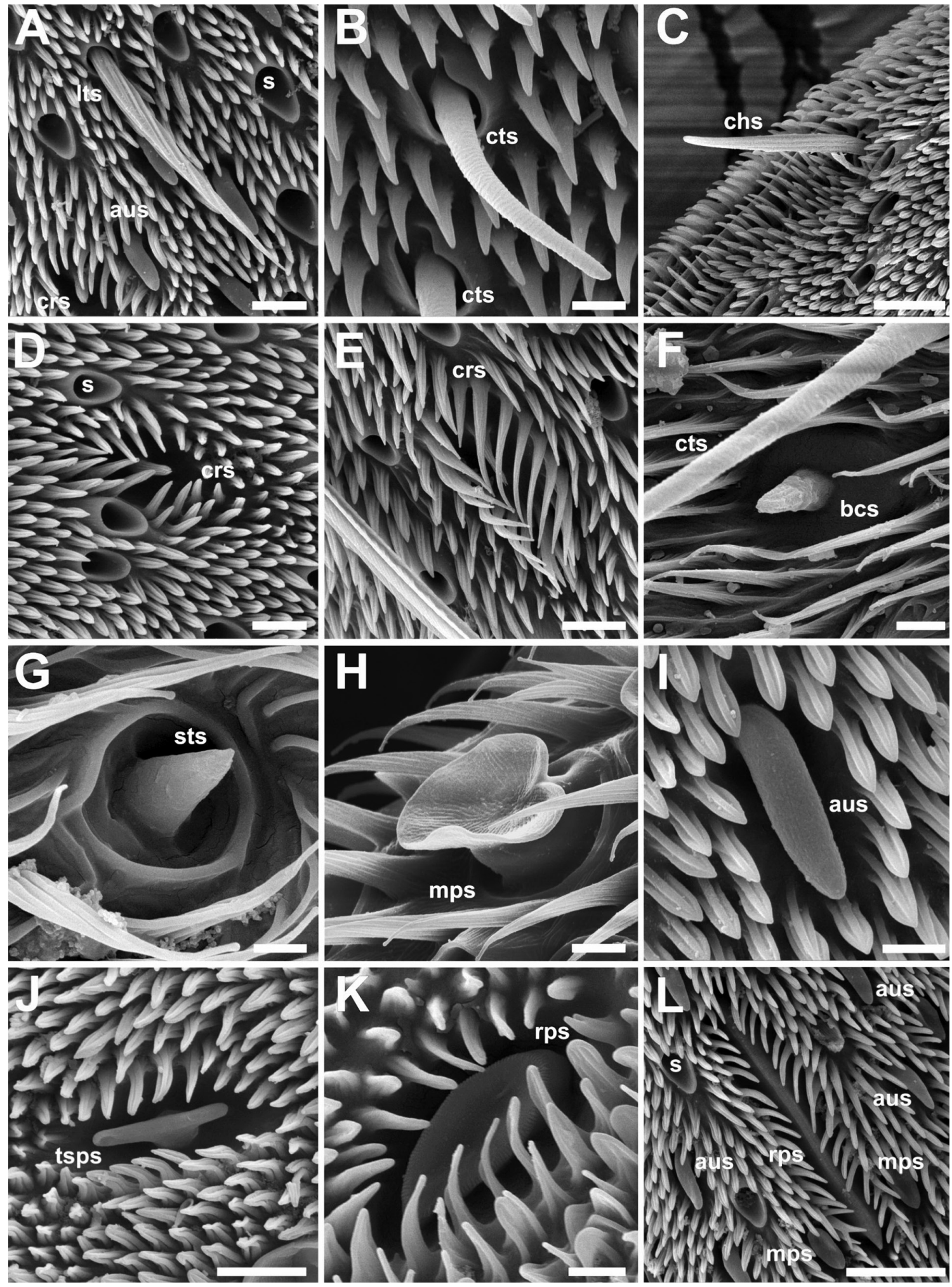

Fig. 2. Antennal sensilla in Hydropsychidae

A - long trichoid sensillum on second flagellomere in M. fenestratum; B - curved trichoid sensilla on first flagellomere in M. fenestratum; C - chaetoid sensillum on $48^{\text {th }}$ flagellomere in M. radiatum; D - common coronary sensillum on $12^{\text {th }}$ flagellomere in M. midas; $\mathrm{E}$ - elongated coronary sensillum on second flagellomere in Ch. comorina; F basiconic sensillum on $11^{\text {th }}$ flagellomere in D. robusta; $G$ - styloconic sensillum on second flagellomere in D. gombak; $\mathrm{H}$ - mushroom-like pseudoplacoid sensillum on $12^{\text {th }}$ flagellomere in P. apicalis; I - auricillic pseudoplacoid sensillum on $6^{\text {th }}$ flagellomere in M. fenestratum; J - T-shaped pseudoplacoid sensillum on first flagellomere in M. radiatum; $\mathrm{K}-$ wide ribbed pseudoplacoid sensillum on $38^{\text {th }}$ flagellomere in Ae. evanescens; $L$ - ribbed pseudoplacoid sensillum on $5^{\text {th }}$ flagellomere in M. fenestratum.

Abbreviations: aus - auricillic pseudoplacoid sensilla; bcs - basiconic sensilla; chs - chaetoid sensilla; crs - coronary sensilla; cts — curved trichoid sensilla; Its — long trichoid sensilla; mps — mushroom-like pseudoplacoid sensilla; rps ribbed pseudoplacoid sensilla; sts - styloconic sensilla; $s$ - empty sockets; tsps - T-shaped pseudoplacoid sensilla. Scale bars: $1 \mu \mathrm{m}$ in G; $2 \mu \mathrm{m}$ in $\mathrm{B}, \mathrm{F}, \mathrm{H}, \mathrm{I}, \mathrm{K} ; 5 \mu \mathrm{m}$ in $\mathrm{A}, \mathrm{D}, \mathrm{E}, \mathrm{J} ; 10 \mu \mathrm{m}$ in $\mathrm{C}, \mathrm{L}$. 

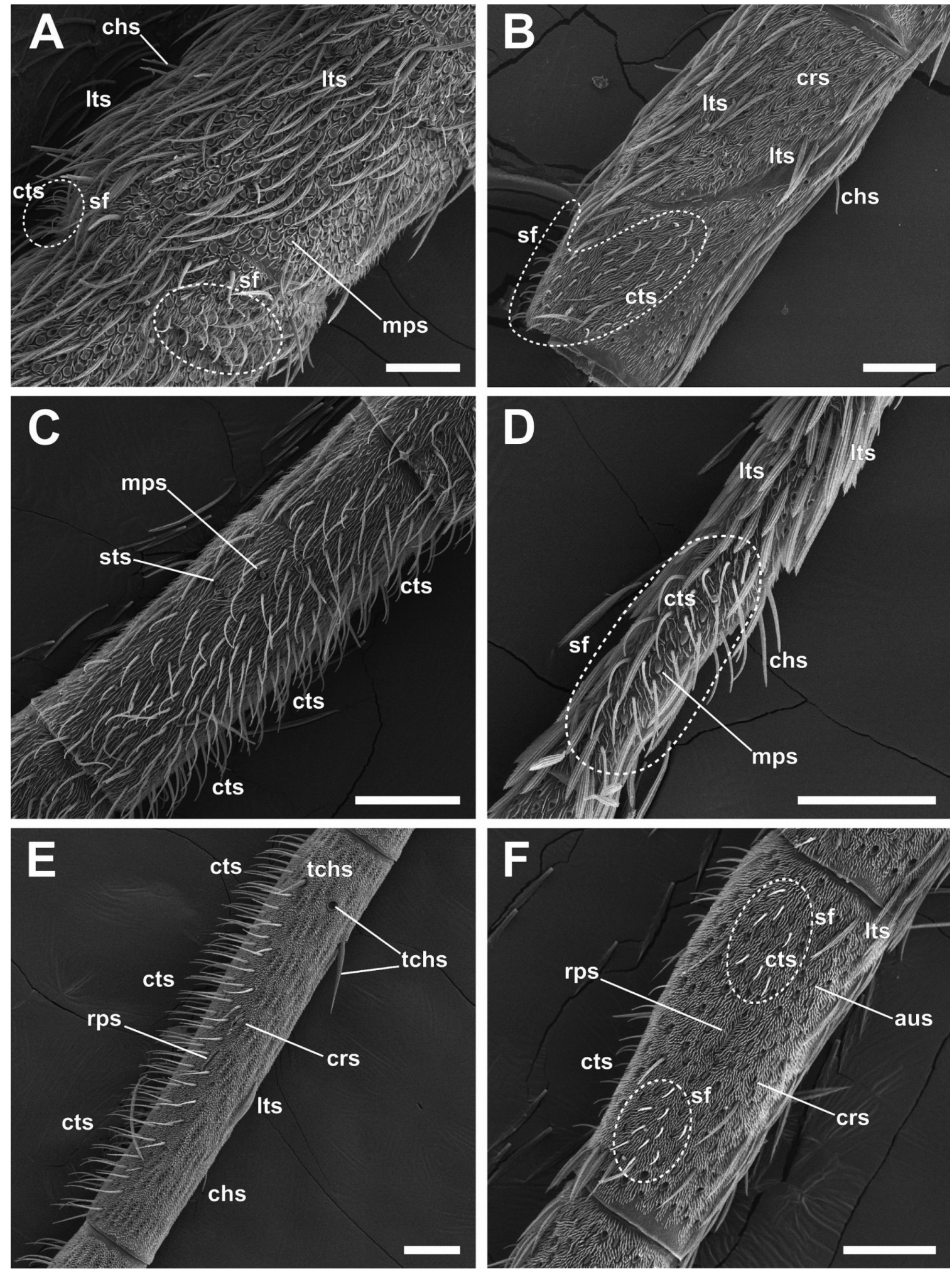

Fig. 3. Structure of antennal surface and sensory fields in Hydropsychidae

A $-4^{\text {th }}$ flagellomere of A. palpata; B $-2^{\text {nd }}$ flagellomere of H. pellucidula; C $-3^{\text {rd }}$ flagellomere of D. dulitensis; $\mathrm{D}-13^{\text {th }}$ flagellomere of S. murina; $\mathrm{E}-12^{\text {th }}$ flagellomere of Centromacronema $s p . ; \mathrm{F}-2^{\text {nd }}$ flagellomere of $M$. fenestratum.

Abbreviations: sf — sensory field; tchs — thick chaetoid sensilla. Scale bars: $50 \mu \mathrm{m}$. 

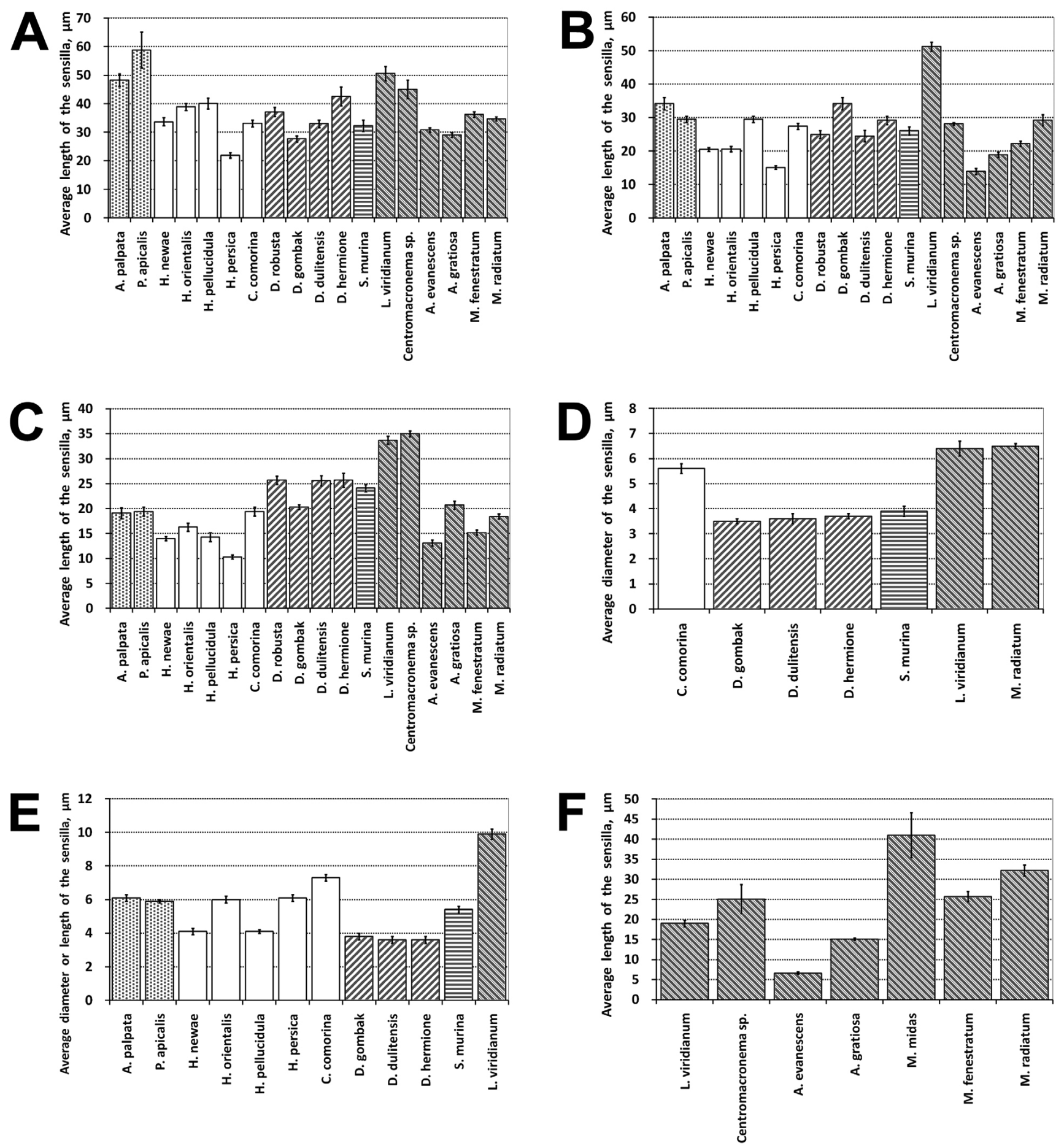

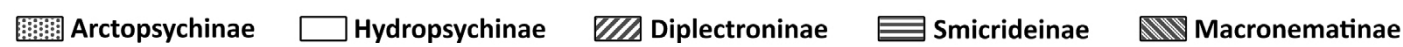

Fig. 4. Size comparison of sensilla in different representatives in Hydropsychidae

A - long trichoid; B - chaetoid; C — curved trichoid; D - styloconic; E - mushroom-like pseudoplacoid; F — ribbed pseudoplacoid.

doptera (Larsson et al., 2002; Faucheux, 2006), these structures have a short finger-shaped cuticular part with non-branching grooves perforated by pores.

T-shaped pseudoplacoid sensilla (Fig. 1P; 2J: tsps) were found in $M$. radiatum. Their average length is $7.5 \pm$ $0.4 \mu \mathrm{m}$. These structures have T-shaped outgrowth oriented in the distal direction and a short rounded base, slightly submerged below the surface and surrounded by microtrichia, which are inclined towards the sensilla. The apical wall of these sensilla is flat or slightly convex and lacks any visible grooves or pores.

Ribbed pseudoplacoid sensilla (Fig. 1Q, R, 2K, L: rps) are present in males of all studied species of the subfamily Macronematinae. They were also found in 
females of L. viridianum, but antennae of M. midas and $M$. fenestratum females lack these sensilla. Ribbed pseudoplacoid sensilla are from $6.6 \pm 0.3 \mu \mathrm{m}$ (A. evanescens) to $41.0 \pm 5.6 \mu \mathrm{m}$ (M. midas) in length (Fig. 4F). The bases and processes of these sensilla are extremely narrowed and elongated towards the antennal apex; their cuticular parts do not rise above the microtrichia. The body of each sensillum resembles a long ridge, triangular in cross section. Proximal parts of the sensilla are merged with the cuticle, while distal parts form a short pointed outgrowth. The apical wall of the sensillum has short and deep transverse grooves with a low number of pores. In Centromacronema sp. the average length of these sensilla is $25.1 \pm 3.6 \mu \mathrm{m}$, but they can vary in size: Particular sensilla are from $10.1 \mu \mathrm{m}$ to $66.4 \mu \mathrm{m}$ in length. The same size diversity is also observed in M. midas with length range from $17.5 \mu \mathrm{m}$ to $69.5 \mu \mathrm{m}$.

One of the studied species, A. evanescens, is characterized by modification of ribbed pseudoplacoid sensilla. In contrast to the common subtype, these sensilla have short and widened oval-shaped processes surrounded by modified microtrichia (Fig. 1Q, 2K). Sensillar bases are narrow, and proximal sides merge with the cuticle. The apical part of each sensillum of this second subtype bears deep and short poreless grooves, which do not cover the whole apical surface and are located only beside the margin. They are shorter than common ribbed sensilla: Their average length does not exceed $6.6 \pm 0.3 \mu \mathrm{m}$.

Coronary sensilla (Fig. 1G, H; 2D, 3D-F: crs) are small pegs, which have more or less rounded sockets. The base of sensilla is fully (Hydropsychinae, Macronematinae, D. dulitensis, S. murina) or partly (Arctopsychinae, D. robusta, D. gombak, D. hermione) surrounded by modified microtrichia. The base diameter varies from $6.1 \pm 0.3 \mu \mathrm{m}$ in D. robusta to $11.9 \pm 0.5 \mu \mathrm{m}$ in Centromacronema sp. In one species, Ch. comorina, most of the coronary sensilla are modified and have sockets elongated parallel to the antennal axis (Fig. 1H; 2E), while the processes of these stretched sensilla have no unique morphological features.

Basiconic sensilla (Fig. 1F; 2F: bcs) were found only in D. robusta. These sensilla are thin and longitudinally striated peg-like structures set on broad rounded bases $(6.0 \pm 0.3 \mu \mathrm{m}$ in diameter). In contrast to coronary sensilla, they are not surrounded by microtrichia.

Styloconic sensilla (Fig. 1I, J; 2G; 3C: sts) are very short peg-like structures with a smooth surface and elevated border of the socket, and were found in $C h$. comorina, D.gombak, D.dulitensis, D. hermione, S. murina, L.viridianum, M.midas and M.radiatum. Their diameter varies from $3.2 \pm 0.1 \mu \mathrm{m}$ in $D$. gombak to $6.4 \pm$ $0.3 \mu \mathrm{m}$ in L. viridianum. Two subtypes of styloconic sensilla were observed only in one species, D. gombak. The first subtype (Fig. 1I) has a typical structure, but sensilla of the second subtype have a convex base, without ele- vated edges of the socket (Fig. 1J). The sensilla processes of the first and second subtypes are $1.7 \pm 0.1 \mu \mathrm{m}$ and $2.3 \pm 0.1 \mu \mathrm{m}$ in length, correspondingly. The diameter of styloconic sensilla in Diplectroninae and Smicrideinae never exceeds $4 \mu \mathrm{m}$, but it is always higher than $5 \mu \mathrm{m}$ in other studied species (Fig. 4D).

\section{Distribution of sensilla}

Sensilla in studied Hydropsychidae can be classified into four distinct types of distribution on the antennal surface (Table 1).

Non-specific distribution is displayed by long trichoid sensilla (in all studied species), mushroom-like pseudoplacoid sensilla (in Arctopsychinae, H. orientalis and Hydronema persica), auricillic pseudoplacoid sensilla (in M.fenestratum), and coronary sensilla (in Ch. comorina, $H$. pellucidula and $H$. orientalis). The large number of sensilla more or less uniformly covers the entire available surface of basal segments, and the apical part of antenna has a small number of more sparsely located sensilla (Fig. 5A). In two species, Centromacronema sp. and Ch. comorina, long trichoid sensilla are arranged in longitudinal lines, as was noted also for Leptoceridae (Tozer, 1982; Ivanov and Melnitsky, 2011).

Specific distribution is typical for the greatest number of sensilla types: chaetoid sensilla (in Ch. comorina and all Macronematinae, except L.viridianum), curved trichoid sensilla (in A.evanescens), mushroomlike pseudoplacoid sensilla (in Diplectroninae, H.pellucidula, H. newae, Ch. comorina, S. murina, L. viridianum and M. midas), auricillic pseudoplacoid sensilla (in D. robusta, A. evanescens, A. gratiosa and M. radiatum), coronary sensilla (in all studied species, except Ch. comorina, $H$.pellucidula and H.orientalis), thick chaetoid sensilla, ribbed pseudoplacoid sensilla, T-shaped pseudoplacoid sensilla, basiconic sensilla and styloconic sensilla.

Patterns of specific distribution are very diverse in Hydropsychidae. The most pronounced variation is observed in pseudoplacoid sensilla. Specifically, distributed mushroom-like pseudoplacoid sensilla usually occur in groups on basal segments, while more distal segments bear single sensilla of this type only on their distal parts. Ribbed pseudoplacoid sensilla are numerous on the first segment of Centromacronema sp. and species of genus Macrostemum, while on other flagellomeres they usually occur singly on the distal part of the flagellomere. These sensilla are solitary on all segments of L.viridianum, including the first one. In particular species (A.evanescens and A.gratiosa) the ribbed pseudoplacoid sensilla occur in large groups every third or fourth segment, while on other segments they are solitary. Auricillic pseudoplacoid sensilla in M. radiatum, A. evanescens and A.gratiosa are found mainly on the first segment, where they are positioned in groups. In one species, M.fenestratum, sensilla 

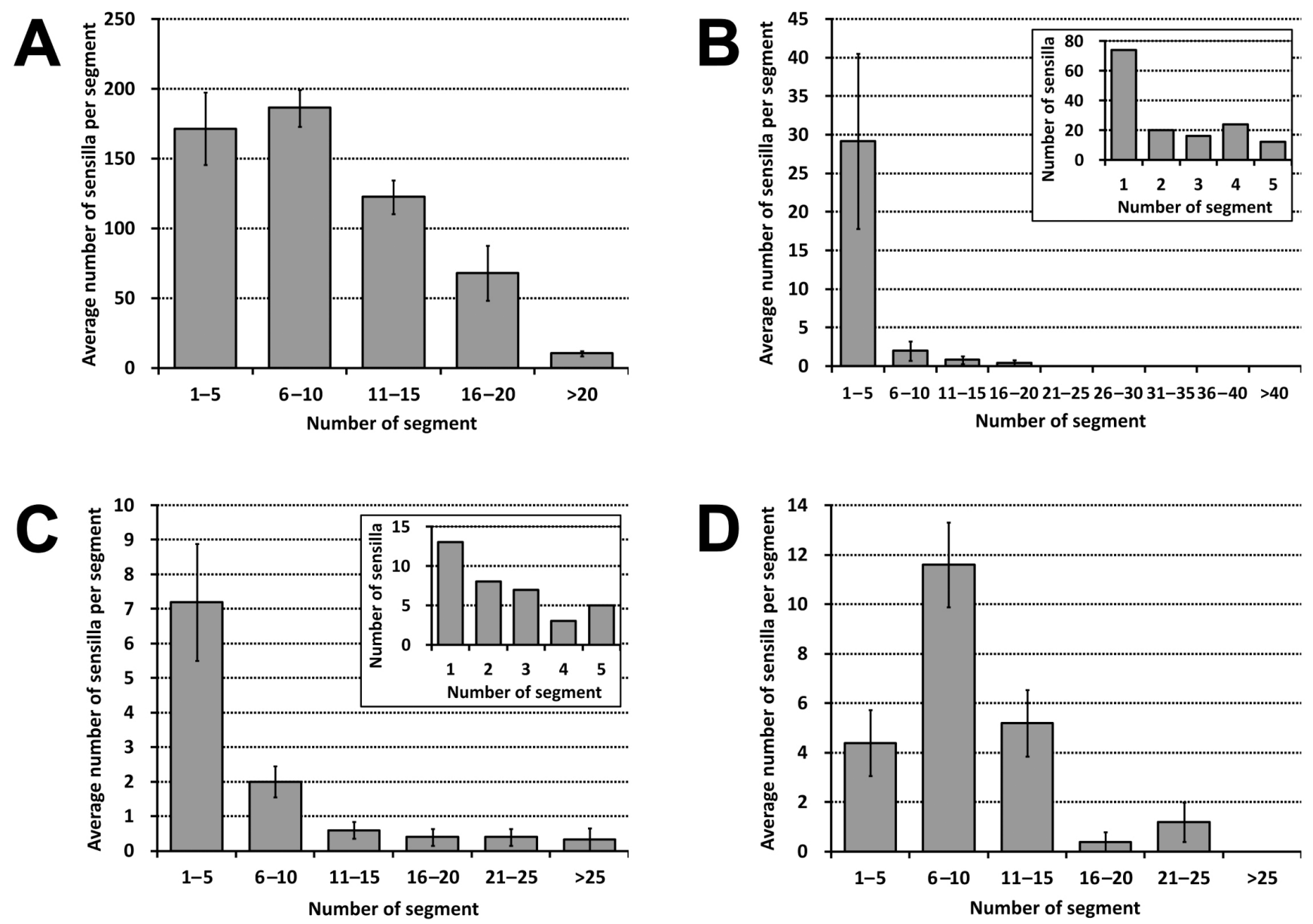

Fig. 5. Four types of quantitative distribution of mushroom-like pseudoplacoid sensilla in Hydropsychidae

A - number of sensilla decreases gradually towards the antennal apex (Arctopsychinae; Hydropsychinae: H. orientalis, Hydronema persica and C. comorina) (Hydronema persica on plot); B - rapid decline of sensilla number (Hydropsychinae: H. newae; Diplectroninae: D. gombak; Macronematinae: M. midas) (H. newae on plot); C - transitional variant of reduction in the average number of sensilla (Diplectroninae: $D$. dulitensis and D. hermione; Smicrideinae: S. murina; Macronematinae: L. viridianum) (L. viridianum on plot); D — number of mushroom-like pseudoplacoid sensilla is the highest on $6-10$ flagellomeres (12 sensilla in average) and decreases on more distal segments (Hydropsychinae: H. pellucidula).

of this type have non-specific distribution on basal segments and occur in clusters on more distal flagellomeres (specific distribution). Auricillic pseudoplacoid sensilla of D. robusta are located in groups on distal parts of segments. Coronary sensilla have a great diversity of placement patterns, which show almost no common features in different representatives of Hydropsychidae. Styloconic sensilla are specifically distributed and positioned solitary in most studied species, but M. midas has a large diffuse group of these sensilla on the first flagellomere.

Curved trichoid sensilla are grouped in sensory fields in most studied species except for A.evanescens, where they are located mainly on the first segment around two large groups of auricillic pseudoplacoid sensilla. Sensory fields are usually observed on basal segments of flagella, where they are always located on ventral or ventrolateral surface (Fig. 3). The number of curved trichoid sensilla in sensory fields decreases towards the antennal apex in all studied species. The curved trichoid sensilla occur solitarily on subapical flagellomeres in most species and thus sensory fields are absent. In Arctopsychinae, Hydropsychinae, S. murina, A.gratiosa, M.midas, M. fenestratum and M.radiatum the sensory fields are diffuse and sensilla of other types occur in gaps between curved trichoid sensilla.

Sensory fields have five different structural types in Hydropsychidae (Fig. 6). In the most basal subfamily, Arctopsychinae, sensory fields occur on distal parts of flagellomeres and are divided into two groups located symmetrically on both sides of the antennal axis (Fig. $3 \mathrm{~A})$. These groups comprise an equal number of sensilla (17-27 in each group on basal segments), which decreases to 2-3 sensilla on subapical segments (Fig. 6A). The same shape of sensory fields is observed in H. newae and H.persica (Hydropsychinae). In the middle of antenna two symmetrical groups of sensilla merge in H. newae, but remain separate on all flagellomeres in Arctopsychinae and H.persica. 
Table 1. Types of sensilla distribution in Hydropsychidae

\begin{tabular}{|c|c|c|c|c|}
\hline \multirow{2}{*}{ Taxon } & \multicolumn{4}{|c|}{ Type of sensilla distribution } \\
\hline & non-specific & specific & sensory fields & fixed \\
\hline Arctopsyche palpata Martynov, 1934 & Its, mps & crs & cts & chs \\
\hline Parapsyche apicalis (Banks, 1908) & Its, mps & crs & cts & chs \\
\hline Hydropsyche newae Kolenati, 1858 & Its & $\mathrm{mps}, \mathrm{crs}$ & cts & chs \\
\hline Hydropsyche orientalis Martynov, 1934 & Its, mps, crs & - & cts & chs \\
\hline Hydropsyche pellucidula (Curtis, 1834) & Its, crs & $\mathrm{mps}$ & cts & chs \\
\hline Cheumatopsyche comorina Navas, 1931 & Its, crs & chs, mps, sts & cts & - \\
\hline Hydronema persica Martynov, 1914 & Its, mps & crs & cts & chs \\
\hline Diplectrona robusta Martynov, 1934 & Its & aus, crs, bcs & cts & chs \\
\hline Diplectrona gombak Olah, 1993 & Its & mps, crs, sts & cts & chs \\
\hline Diplectrona dulitensis Kimmins, 1955 & Its & $\mathrm{mps}$, crs, sts & cts & chs \\
\hline Diplectrona hermione Malicky, Chantaramongkol, 2002 & Its & mps, crs, sts & cts & chs \\
\hline Smicridea murina McLachlan, 1871 & Its & mps, crs, sts & cts & chs \\
\hline Leptonema viridianum Navas, 1916 & Its & $\mathrm{mps}$, rps, crs, sts & cts & chs \\
\hline Centromacronema sp. & Its & chs, tchs, rps, crs & cts & - \\
\hline Aethaloptera evanescens (McLachlan, 1880) & Its & chs, tchs, cts, rps, aus, crs & - & - \\
\hline Amphipsyche gratiosa Navas, 1922 & Its & chs, rps, aus, crs & cts & - \\
\hline Macrostemum fenestratum (Albarda, 1881) & $\begin{array}{l}\text { Its, aus (proximal } \\
\text { segments) }\end{array}$ & $\begin{array}{l}\text { chs, mps, rps, crs, aus } \\
\text { (distal segments) }\end{array}$ & cts & - \\
\hline Macrostemum radiatum (McLachlan, 1872) & Its & chs, rps, aus, tsps, crs, sts & cts & - \\
\hline Macrostemum midas Malicky, Chantaramongkol, 1998 & Its & chs, mps, rps, crs, sts & cts & - \\
\hline
\end{tabular}

Colors in the taxon column indicate subfamilies: yellow — Arctopsychinae, light green — Hydropsychinae, purple — Diplectroninae, blue Smicrideinae, dark green - Macronematinae.

Sensory fields of another type, U-shaped, were found in some Hydropsychinae (H.orientalis and H.pellucidula) (Fig. 3B). They are positioned on the distal part of the segment and contain 13-64 curved trichoid sensilla on basal flagellomeres (Fig. 6B, D). The number of sensilla in sensory fields in these species decreases to $1-3$ on subapical segments.

Sensory fields covering the whole ventrolateral surface of the segment occur widely in Hydropsychidae (Diplectroninae, Ch. comorina, S. murina, Centromacronema sp., and A. gratiosa) (Fig. 3C; 6B-E). These sensory fields comprise from 50 (A.gratiosa) to 300 (D.hermione) curved trichoid sensilla on basal segments. Sensory fields of this shape are split into proximal and distal parts in the middle of antenna in most Diplectroninae (D.hermione, D.gombak and D.dulitensis) and in Ch. comorina (Hydropsychinae); in D. robusta and S. murina they remain on distal parts of flagellomeres and are not split (Fig. 3D); in Centromacronema sp. and A.gratiosa sensory fields become narrower (Fig. 3E). Subapical segments bear 0-3 curved trichoid sensilla in most species with this shape of sensory fields, while in D. robusta and S. murina the number of sensilla in sensory fields remains relatively high (15-20).

Species of genus Macrostemum have longitudinally divided sensory fields, which cover almost the entire ventrolateral surface of the segment (Fig. 6C). These sensory fields are present mainly on the first two segments. They are most developed on the first segment, which has approximately 750 (M.fenestratum) to 1200 (M.midas) curved trichoid sensilla. In M.fenestratum sensory fields of second and third segments are divided into four groups of curved trichoid sensilla (Fig. 3F).

Sensory fields are divided into larger distal and smaller proximal parts in L.viridianum (Fig. 6C). The number of curved trichoid sensilla is the highest on the first segment (260 sensilla). The proximal part of these sensory fields reduces beginning with the fifth segment. Subapical segments bear 3-4 curved trichoid sensilla on their distal parts.

Fixed distribution pattern is common for chaetoid sensilla in Arctopsychinae, Diplectroninae, $\mathrm{Hy}-$ 

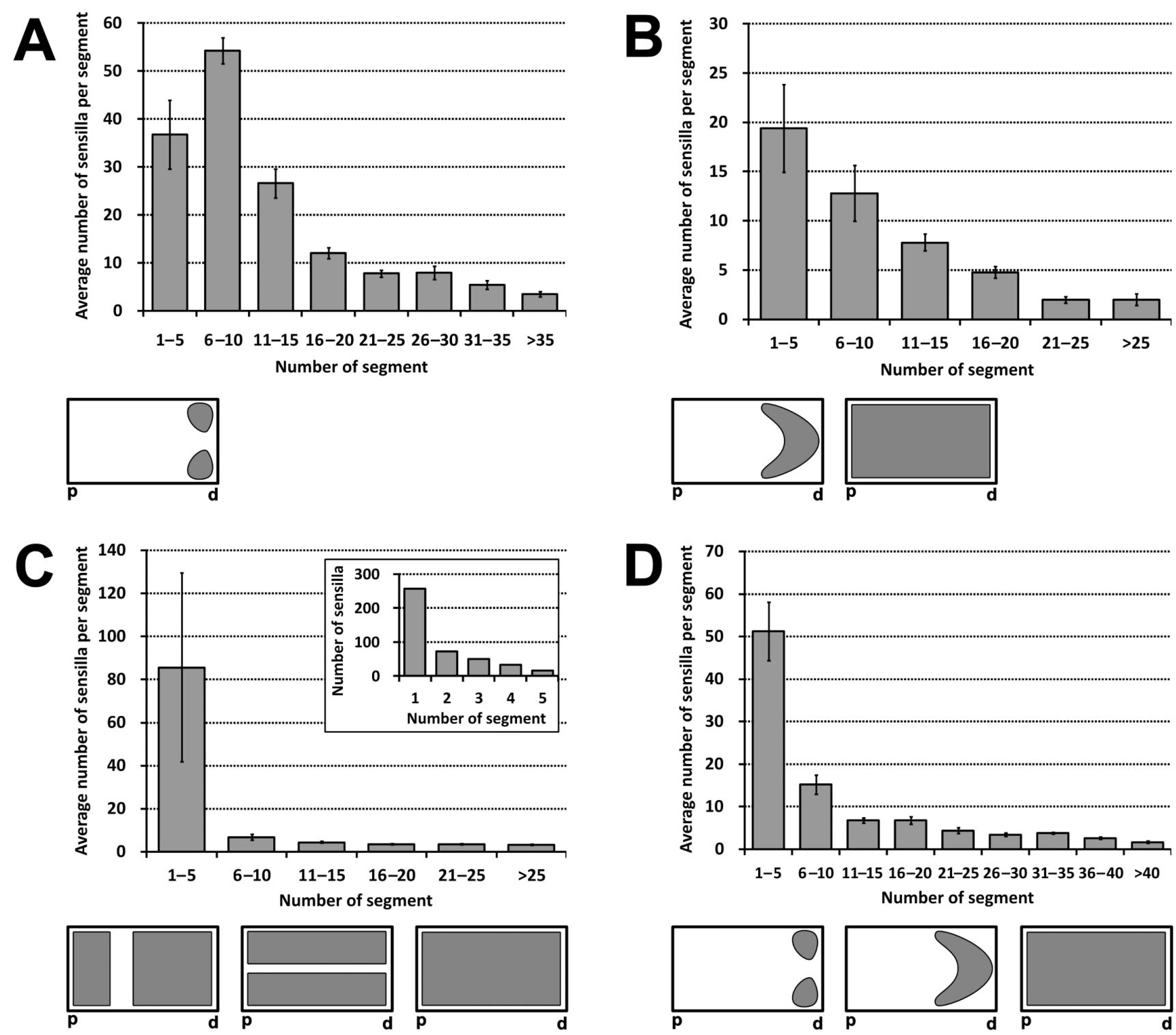

Number of segment
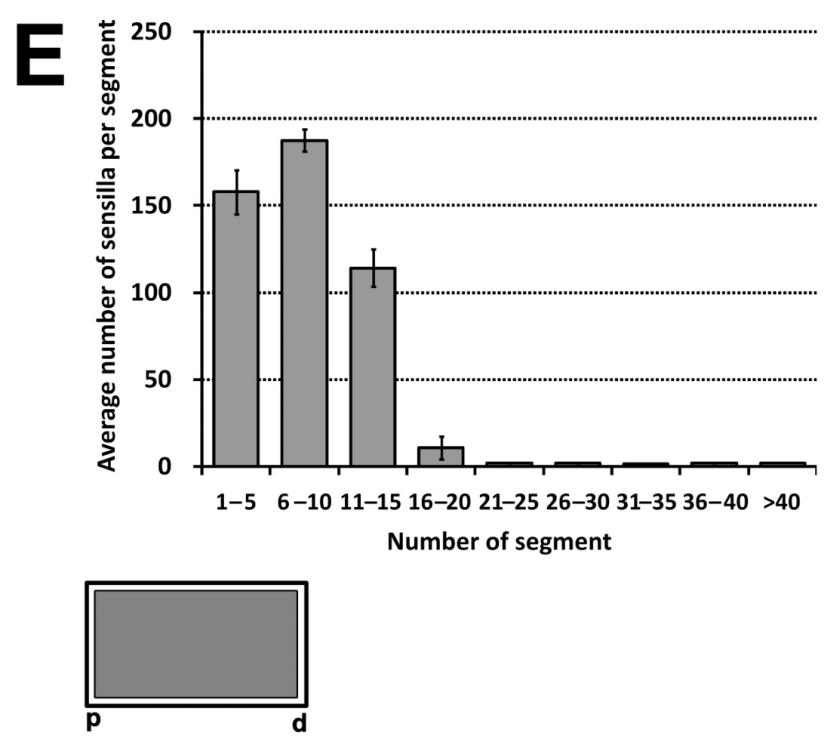
dropsychinae (except Ch. comorina), S. murina and L. viridianum. In this case sensilla are gradually shifted to distal parts of segments towards the antennal apex in S. murina and L. viridianum. Distribution of chaetoid sensilla in Ch. comorina and all Macronematinae except L. viridianum is similar to fixed, but the position of the solitary sensilla is more labile. In most studied species the number of chaetoid sensilla is constant along the antenna (from 7 in L.viridianum to 12 in A.palpata) and slightly decreases on subapical segments. The basal flagellomeres of Diplectroninae, Smicrideinae, Centromacronema sp. and $H$. persica bear a smaller number of chaetoid sensilla (0-4) than more distal segments.

\section{Discussion}

Besides the common types of sensilla (long trichoid sensilla, chaetoid sensilla, curved trichoid sensilla, mushroom-like pseudoplacoid sensilla, coronary sensilla, basiconic sensilla and styloconic sensilla) occurring in most caddisflies (Melnitsky and Ivanov, 2011; Ivanov and Melnitsky, 2016), three unique types were found within the family Hydropsychidae: T-shaped pseudoplacoid sensilla, ribbed pseudoplacoid sensilla, and thick chaetoid sensilla.

The great diversity of sensilla is based mainly on modifications of mushroom-like pseudoplacoid sensilla: They are transformed into auricillic, ribbed and T-shaped pseudoplacoid sensilla in different representatives of the subfamily Macronematinae. The presence of ribbed pseudoplacoid sensilla seems to be an apomorphic character of Macronematinae. M. radiatum has the most unusual set of these sensilla: Antennae of this species bear ribbed, auricillic and T-shaped pseudoplacoid sensilla. In one studied species, A.evanescens, ribbed pseudoplacoid sensilla resemble mushroom-like ones: they have slightly widened and concave caps.

Other sensilla types also show structural modifications: long trichoid, chaetoid, coronary, and styloconic sensilla. Coronary sensilla in Arctopsychinae, D. robusta, D. gombak and D. hermione have unevenly developed microtrichia as in Rhyacophilidae (Valuyskiy et al., 2017), Ecnomidae (Valuyskiy et al., 2019), Glossosomatidae (Valuyskiy et al., 2020a) and Apataniidae (Valuyskiy et al., 2020b). D. gombak has two different subtypes of styloconic sensilla, as was noted in Philopotamidae (Melnitsky et al., 2018) and Plutellidae (Lepidoptera) (Yan et al., 2017). No special features in the structure of curved trichoid and basiconic sensilla were found.

In contrast to the majority of previously studied caddisfly families, Hydropsychidae displays a high diversity of sensilla distribution patterns due to several factors. Firstly, the transition from non-specific to specific distribution in mushroom-like pseudoplacoid sensilla (Diplectroninae, H.pellucidula, H. newae, Ch. comorina, S.murina, L. viridianum, and M. midas) is correlated with a low number of these structures (Fig. 5). Specifically, distributed pseudoplacoid sensilla occupy only a particular area of each segment; thus, they have smaller numbers compared to pseudoplacoid sensilla with non-specific distribution. Ribbed (Macronematinae), auricillic (D. robusta, A.evanescens, A.gratiosa and $M$. radiatum), and T-shaped (M.radiatum) pseudoplacoid sensilla inherit specific distribution from the mushroom-like ones. Secondly, the sensory fields show great differences in shape and sensilla number. Thirdly, coronary sensilla have a wide variety of distribution pattern, which usually has no similarities even in closely related species from the same subfamily. Other types of sensilla, which have non-specific or specific distribution, display the same patterns in their localization as in other studied caddisfly families (Ivanov and Melnitsky, 2011; Melnitsky and Ivanov, 2016; Melnitsky et al., 2018; Valuyskiy et al., 2017, 2019, 2020a, 2020b).

As it was noted above, most modifications of sensilla distribution are displayed by curved trichoid and mushroom-like pseudoplacoid sensilla. Basal flagellomeres always have the largest numbers of sensilla in sensory fields; the sensilla counts decrease gradually or abruptly towards the antennal apex in different representatives of these subfamilies.

Sensory fields in Arctopsychinae seem to have the most archaic distributional pattern compared to all other Hydropsychidae: Each segment has two sensory fields with a small number of curved trichoid sensilla (up to 55 per segment); they are most numerous on the $6^{\text {th }}-10^{\text {th }}$ segments (Fig. 6A). A similar pattern was noted in the representatives of genus Philopotamus (Melnitsky et al., 2018) from the family Philopotamidae supposed to be basal for Annulipalpia. This pattern is modified in Di-

Fig. 6. Quantitative distribution of curved trichoid sensilla and shape variation of sensory fields in Hydropsychidae

A - the number of curved trichoid sensilla reaches its maximum on 6-10 segments (up to 55 per segment) and decreases on more distal part of antenna in Arctopsychinae (A. palpata on plot); B - curved trichoid sensilla in U-shaped (Hydropsychinae: H. orientalis) or wide (Diplectroninae: $D$. robusta) sensory fields are most numerous on 1-5 flagellomeres and their number decreases gradually to the antennal apex (H. orientalis on plot); C - rapidly decreasing pattern of wide and dissected sensory fields (Diplectroninae: D. gombak and D. dulitensis; Macronematinae, except Centromacronema sp.) (L. viridianum on plot); D - transitional type between B and C, with U-shaped, wide, or twin fields (Hydropsychinae, except H. orientalis; Diplectroninae: D. hermione; Smicrideinae: S. murina) (H. newae on plot); $E-$ number of sensilla in large sensory fields reaches its maximum on 6-10 flagellomeres and diminishes dramatically on segments distal to the $15^{\text {th }}$ (Macronematinae: Centromacronema sp.). Abbreviations: $\mathrm{p}$ - proximal; $d$ - distal end of segment. 
plectroninae and Smicrideinae, which have a tendency for expansion of sensory fields: they occupy the entire ventrolateral surface of the segment.

The members of subfamily Hydropsychinae show a high diversity in shape of sensory fields and number of curved trichoid sensilla. The pattern of sensory fields in some representatives of this subfamily is similar to Arctopsychinae (Hydropsyche newae and Hydronema persi$\mathrm{ca}$ ), but the highest number of sensilla in sensory fields is always observed on the 1st-5th segments (Fig. 6B, D). In some species of Hydropsychinae this pattern undergoes a modification: A segment bears one U-shaped sensory field on its distal part (H. orientalis and H.pellucidula) (Fig. 6B, D). Such diversity may indicate formation of several evolutional paths in this group.

Representatives of subfamily Macronematinae show reduction of sensory fields: Basal segments of these species bear a large number of curved trichoid sensilla in sensory fields, but the count of sensilla decreases rapidly to $0-4$ sensilla per segment starting with the $6^{\text {th }}-10^{\text {th }}$ segments (Fig. 6C). Reduction of sensory fields was also found in two endemic tribes of Apataniidae (Valuyskiy et al., 2020b), where the number of curved trichoid sensilla is low on all segments. The great diversity of sensory fields' shape and their quantitative parameters in closely related species of Hydropsychinae and Macronematinae may indicate fast function-dependent evolution of antennal sensory surface in these groups.

The initial state of pseudoplacoid sensilla in Hydropsychidae is characterized by mushroom-like shape and non-specific distribution with the highest number of sensilla on the $1^{\text {st }}-5^{\text {th }}$ segments (Fig. $5 \mathrm{~A}$ ). This state is typical of Arctopsychinae and some Hydropsychinae (H.orientalis and Hydronema persica). It is modified in Diplectroninae, Smicrideinae and partly in Hydropsychinae (H.pellucidula, H. newae and Ch. comorina): Mushroom-like pseudoplacoid sensilla acquire specific distribution in these subfamilies. In the most advanced subfamily, Macronematinae, these specifically distributed sensilla are transformed into new structural types of pseudoplacoid sensilla (ribbed, auricillic and T-shaped pseudoplacoid sensilla), which also have specific distribution. Pseudoplacoid sensilla of different types have very variable patterns of specific distribution in Macronematinae. High diversity of pseudoplacoid sensilla distribution was also shown for Rhyacophilidae, which have a tendency for structural differentiation of these sensilla (Valuyskiy et al., 2017).

In conclusion, it can be assumed that the antennal sensory surface of Hydropsychidae undergoes largescale evolution, which affects the structure of the sensillar cuticular part (ribbed, auricillic and T-shaped pseudoplacoid sensilla; thick chaetoid sensilla), localization of sensilla and their number. These evolutional changes may be function-related and lead to a great diversity of antennal sensory surface features within the family. The functional importance of these modifications remains unclear. While representatives of the subfamily Arctopsychinae - traditionally considered a basal taxon in the family Hydropsychidae (Schefter, 1996; Geraci et al., 2005; Geraci, 2007) - have an archaic sensory surface structure without unique characters, the rest of the studied subfamilies have many advanced features. Characters related to shape, size, number and distribution of the sensilla in the future can be used for combined analysis of morphological features and the COI data, which will help to reveal key patterns of antennal sensory surface evolution in Hydropsychidae.

\section{Acknowledgments}

The authors are grateful to fellow colleagues who kindly provided the material for this study: O. Flint and N. Yu. Kluge. We are appreciative to anonymous reviewers of our article for their important corrections and suggestions.

\section{References}

Chapman, R. F. 1998. The Insects: Structure and Function. 771 pp. Cambridge University Press, Cambridge. https:// doi.org/10.1017/CBO9780511818202

Faucheux, M.J. 2004. Antennal sensilla of Trichoptera and Lepidoptera: Phylogenetic considerations. Bulletin van het Koninklijk Belgisch Instituut voor Natuurwetenschappen, Entomologie 128(74):69-71.

Faucheux, M. J. 2006. Antennal sensilla of male Lophocorona pediasia Common, 1973 and their phylogenetic implications (Lepidoptera, Lophocoronidae). Annales de la Société Entomologique de France 42(1):113-118. https://doi.or g/10.1080/00379271.2006.10697456

Fischer, F. C. J. 1963. Hydropsychidae, Arctopsychidae. Trichopterorum Catalogus 4. 223 pp. Nederlandsche Entomologische Vereeniging, Amsterdam.

Frania, H. E. and G. B. Wiggins. 1997. Analysis of morphological and behavioural evidence for the phylogeny and higher classification of Trichoptera. Royal Ontario Museum, Toronto, Life Sciences Contribution 160. https://doi. org/10.5962/bhl.title.53487

Geraci, C. 2007. Phylogeny and classification of Hydropsychidae subfamilies and genera of the World (Insecta: Trichoptera). 191 pp. All Dissertations 160.

Geraci, C. J., Kjer, K. M., Morse, J. C., and Blahnik, R. J. 2005. Phylogenetic relationships of Hydropsychidae subfamilies based on morphology and DNA sequence data; pp. 131-136 in Tanida, K. and Rossiter, A. (eds), Proceedings of the $11^{\text {th }}$ International Symposium on Trichoptera. Tokai University Press, Kanagawa, Japan.

Ivanov, V.D. and Melnitsky, S.I. 2011. Structure and morphological types of the antennal olfactory sensilla in Phryganeidae and Limnephilidae (Insecta: Trichoptera). Zoosymposia 5:210-234. https://doi.org/10.11646/ zoosymposia.5.1.16

Ivanov, V. D. and Melnitsky, S. I. 2016. Diversity of the olfactory sensilla in caddisflies (Trichoptera). Zoosymposia 10:224233. https://doi.org/10.11646/zoosymposia.10.1.20

Kjer, K. M., Thomas, J. A., Zhou, X., Frandsen, P. B., Prendini, E., and Holzenthal, R. W. 2016. Progress on the phylogeny of caddisflies (Trichoptera). Zoosymposia 10(1):248-256. https://doi.org/10.11646/zoosymposia.10.1.23 
Kubiak, M., Beckmann, F., and Friedrich, F. 2015. The adult head of the annulipalpian caddisfly Philopotamus Iudificatus Mclachlan, 1878 (Philopotamidae), mouthpart homologies, and implications on the ground plan of Trichoptera. Arthropod Systematics and Phylogeny 73(3):351-384.

Larsson, M. C., Hallberg, E., Kozlov, M. V., Francke, W., Hansson, B.S., and Löfstedt, C. 2002. Specialized olfactory receptor neurons mediating intra- and interspecific chemical communication in leafminer moths Eriocrania spp. (Lepidoptera: Eriocraniidae). The Journal of Experimental Biology 205:989-998. https://doi.org/10.1242/ jeb.205.7.989

Levanidova, I. M. 1982. Amphibiotic insects of mountain region of the Far East of the USSR. 215 pp. Nauka Publ., Leningrad. (In Russian)

Martynov, A.V. 1924. Caddisflies. Practical Entomology. 384 pp. Izdatel'stvo akademii nauk SSSR Publ., Leningrad. (In Russian)

Melnitsky, S. I. and Ivanov, V. D. 2011. Structure and localization of sensilla on antennae of caddisflies (Insecta: Trichoptera). Journal of Evolutionary Biochemistry and Physiology 47(6):593-602. https://doi.org/10.1134/ S0022093011060111

Melnitsky, S. I., Ivanov, V. D., Valuyskiy, M. Yu., Zueva, L. V., and Zhukovskaya, M.I. 2018. Comparison of sensory structures on the antenna of different species of Philopotamidae (Insecta: Trichoptera). Arthropod Structure and Development 47:45-55. https://doi.org/10.1016/j. asd.2017.12.003

Morse, J. C. 2020. Trichoptera World Checklist. http://entweb. sites.clemson.edu/database/trichopt/

Schefter, P. W. 1996. Phylogenetic relationships among subfamily groups in the Hydropsychidae (Trichoptera) with diagnoses of the Smicrideinae, new status, and the Hydropsychinae. Journal of the North American Benthological Society 15:615-633. https://doi.org/10.2307/1467812

Schmid, F. 1968. La famille des Arctopsychides (Trichoptera). Memoires de la Societe Entomologique de Quebec 1:1-84.

Sinitsina, E. E. and Chaika, S. Yu. 2006. Electron microscopy of chemoreceptor organs of Insects: An Atlas. 334 pp. Moscow State University, Moscow. (In Russian)
Snodgrass, R. E. 1935. Principles of insect morphology. 667 pp. McGraw-Hill, New York; London.

Thomas, J. A., Frandsen, P. B., Prendini, E., Zhou, X., and Holzenthal, R.W. 2020. A multigene phylogeny and timeline for Trichoptera (Insecta). Systematic Entomology 45(3):670-686. https://doi.org/10.1111/syen.12422

Tozer, W. 1982. External antennal morphology of the adult and larva of Nectopsyche albida (Walker) (Trichoptera: Leptoceridae). Freshwater Invertebrate Biology 1(1):3543. https://doi.org/10.2307/3259442

Yan, X-Z., Deng, C.-P., Xie, J.-X., Wu, L.-J., and Sun, X.-J. 2017. Distribution patterns and morphology of sensilla on the antennae of Plutella xylostella (L.) - A scanning and transmission electron microscopic study. Micron 103:111. https://doi.org/10.1016/j.micron.2017.08.002

Valuyskiy, M. Yu., Melnitsky, S. I., and Ivanov, V. D. 2017. Structure of antennal sensilla in the caddisfly genus Rhyacophila Pictet (Trichoptera, Rhyacophilidae). Entomological Review 97(6):703-722. https://doi.org/10.1134/ S001387381706001X

Valuyskiy, M. Yu., Melnitsky, S. I., and Ivanov, V. D. 2019. Comparative analysis of antennal surfaces in adult caddisflies of the genus Ecnomus McLachlan (Trichoptera, Ecnomidae). Entomological Review 99(3):302-309. https:// doi.org/10.1134/S0013873819030035

Valuyskiy, M. Yu., Melnitsky, S. I., and Ivanov, V. D. 2020a. Diversity and distribution of antennal sensilla in Glossosomatidae in comparison with other basal families of caddisflies (Insecta: Trichoptera). Zoosymposia 18:179-190. https://doi.org/10.11646/zoosymposia.18.1.21

Valuyskiy, M. Yu., Melnitsky, S. I., and Ivanov, V.D. 2020 b. Structure and evolution of antennal sensory surface in endemic caddisfly tribes Baicalinini and Thamastini (Trichoptera: Apataniidae) from the lake Baical. Journal of Evolutionary Biochemistry and Physiology 56:318-332. https://doi.org/10.1134/S0022093020040031

Uy, C. J. C., Kang, J.H., Morse, J. C., and Bae, Y.J. 2019. Phylogeny of Macronematinae (Trichoptera: Hydropsychidae) based on molecular and morphological analyses. The Canadian Entomologist 151(6):696-716. https://doi. org/10.4039/tce.2019.57 